
\title{
Work stress and risk of cardiovascular mortality:
prospective cohort study of industrial employees
}

Mika Kivimäki, Päivi Leino-Arjas, Ritva Luukkonen, Hilkka Riihimäki, Jussi Vahtera and Juhani Kirjonen

BMJ 2002;325;857-

doi:10.1136/bmj.325.7369.857

Updated information and services can be found at:

http://bmj.com/cgi/content/full/325/7369/857

These include:

References This article cites 22 articles, 13 of which can be accessed free at: http://bmj.com/cgi/content/full/325/7369/857\#BIBL

44 online articles that cite this article can be accessed at: http://bmj.com/cgi/content/full/325/7369/857\#otherarticles

Rapid responses 11 rapid responses have been posted to this article, which you can access for free at: http://bmj.com/cgi/content/full/325/7369/857\#responses

You can respond to this article at:

http://bmj.com/cgi/eletter-submit/325/7369/857

Email alerting Receive free email alerts when new articles cite this article - sign up in the box at service the top left of the article

Topic collections Articles on similar topics can be found in the following collections

\section{Sociology (345 articles)}

Occupational Health (1297 articles)

Other Cardiovascular Medicine (2118 articles)

Other Public Health (2724 articles)

Psychology (388 articles)

Ischaemic heart disease (2169 articles)

Socioeconomic Determinants of Health (872 articles)

Correction A correction has been published for this article. The contents of the correction have been appended to the original article in this reprint. The correction is available online at:

http://bmj.com/cgi/content/full/325/7377/1386

\section{Notes}

To order reprints follow the "Request Permissions" link in the navigation box

To subscribe to $B M J$ go to:

http://resources.bmj.com/bmj/subscribers 


\section{Papers}

Downloaded from bmj.com on 14 April 2008

\section{Work stress and risk of cardiovascular mortality: prospective cohort study of industrial employees}

Mika Kivimäki, Päivi Leino-Arjas, Ritva Luukkonen, Hilkka Riihimäki, Jussi Vahtera, Juhani Kirjonen

\begin{abstract}
Objective To examine the association between work stress, according to the job strain model and the effort-reward imbalance model, and the risk of death from cardiovascular disease.

Design Prospective cohort study. Baseline examination in 1973 determined cases of cardiovascular disease, behavioural and biological risks, and stressful characteristics of work. Biological risks were measured at 5 year and 10 year follow up. Setting Staff of a company in the metal industry in Finland.

Participants 812 employees (545 men, 267 women) who were free from cardiovascular diseases at baseline.

Main outcome measure Cardiovascular mortality 1973-2001 from the national mortality register.

Results Mean length of follow up was 25.6 years. After adjustment for age and sex, employees with high job strain, a combination of high demands at work and low job control, had a 2.2-fold (95\% confidence interval 1.2 to 4.2 ) cardiovascular mortality risk compared with their colleagues with low job strain. The corresponding risk ratio for employees with effort-reward imbalance (low salary, lack of social approval, and few career opportunities relative to efforts required at work) was 2.4 (1.3 to 4.4). These ratios remained significant after additional adjustment for occupational group and biological and behavioural risks at baseline. High job strain was associated with increased serum total cholesterol at the 5 year follow up. Effort-reward imbalance predicted increased body mass index at the 10 year follow up.

Conclusions High job strain and effort-reward imbalance seem to increase the risk of cardiovascular mortality. The evidence from industrial employees suggests that attention should be paid to the prevention of work stress.
\end{abstract}

\section{Introduction}

Concern is increasing about the adverse effects that work stress may have on health, particularly the risk of cardiovascular disease. Two models identifying stressful components of the psychosocial work environment have received particular attention: the job strain model $^{12}$ and, more recently, the effort-reward imbal- ance model. ${ }^{3}$ In spite of the large body of research on these models, ${ }^{3-7}$ no previous study has tested them simultaneously in relation to cardiovascular mortality.

The job strain model posits that a combination of high work demands and low job control at work, called job strain, is a health risk for employees. ${ }^{2}$ The few studies on cardiovascular mortality partly support the model. Alterman et al showed a moderate prospective association between job strain and fatal cardiovascular disease. ${ }^{8}$ Other investigations have linked cardiovascular mortality to a combination of high demands, low resources, and low income, ${ }^{9}$ to job control only, ${ }^{10}$ and to neither job control, work demands, nor their interaction. ${ }^{11}$

The effort-reward imbalance model considers the impact of labour market conditions on health in addition to the more proximal job conditions. ${ }^{3}$ Health risk derives from the mismatch between high efforts at work and low reward received in turn. Rewards concern money, social approval, job security, and career opportunities. Direct evidence of cardiovascular mortality has been lacking. Results from the Whitehall II study showed an association between effort-reward imbalance and incidence of coronary heart disease, as indicated by self reports. ${ }^{12}$ Cross sectional findings have revealed associations of effort-reward imbalance with precursors of cardiovascular disease, such as hypertension, high concentrations of low density lipoprotein cholesterol, lowered vagal tone, and impaired fibrinolytic capacity. ${ }^{13-15}$

Cardiovascular disease is the leading cause of death in modern civilisations. Work stress models focusing on aspects of the workplace, work organisation, and labour market conditions may offer promising opportunities for theory based intervention. We aimed to test the extent to which the work stress models can explain deaths from cardiovascular disease.

\section{Methods}

\section{Study population}

The study sample was drawn from the employees $(\mathrm{n}=4570$ in 1973) of the Valmet factories in Jyväskylä, central Finland, which manufacture paper machines, tractors, firearms, gauges, and so on. The work tasks varied from foundry work and heavy engineering to precision engineering and clerical and administrative work. The study population comprised people who had been employed by Valmet for at least 15 months in
Department of
Psychology,
University of
Helsinki, PO Box
13, FIN-00014,
Finland
Mika Kivimäki
acting professor
Päivi Leino-Arjas
senior researcher
Ritva Luukkonen
statistician
Hilkka Riihimäki
professor
Jussi Vahtera
senior researcher
Department of
Physical Education,
University of
Jyväskylä,Jyväskylä,
Finland
Juhani Kirjonen
emeritus professor
Correspondence to
M Kivimäki
mika.kivimaki@
occuphealth.fi
bmj.com 2002;325:857 
January 1973 ( $\mathrm{n}=2653)$. We selected a systematic sample of 902 participants in strata by sex, age (born in 1925 or earlier, born in 1926-45, born in 1946 or later), and occupational group (managers, other office staff, skilled workers, semiskilled workers). ${ }^{16}$ People who refused to participate were replaced by new participants from a reserve list. We gathered data by questionnaire, interviews, and clinical examinations. After exclusion of people with cardiovascular disease at baseline, the study cohort comprised 812 employees. Follow up examinations included measurement of blood pressure, cholesterol concentration, and body mass index in $1978(\mathrm{n}=674)$ and in $1983(\mathrm{n}=594)$. We obtained ethical approval for the study from the Hospital district of Helsinki and Uusimaa ethics committee for research in occupational health and safety.

\section{Work stress questionnaire}

We used self assessment scales used to measure the components of the job strain model and the effort-reward imbalance model. ${ }^{16}$ The four questions on work demands deal with the degree of responsibility at work, task difficulty, and mental load (Cronbach's $\alpha$ reliability $=0.67$ ), and the 12 questions on job control concern decision authority and skill discretion $(\alpha=0.78)$. (Sample questions: "How mentally straining do you consider your work?" "Do you learn new things in your work?") The nine questions on effort at work indicate pace of work and physical and mental load $(\alpha=0.72)$, and the 16 questions on rewards measure satisfaction with income, fairness of supervision, job security, and promotion prospects $(\alpha=0.80)$. (Sample questions: "How great is the strain due to haste in your work?" "If changes or reorganisation take place at your workplace, how great is your risk of getting laid off?") All the questions required responses on Likert-type response formats (for example, 1="no strain" to $5=$ =very great strain"). Each scale was constructed by summing the response scores on the individual questions. We divided the resulting scores into thirds to indicate low, intermediate, and high levels on each scale.

We used the work demand and job control scales to create the job strain indicator. This indicator had three categories: high job strain (high or intermediate demands combined with low control), low job strain (low demands combined with high or intermediate control), and intermediate job strain (all other combinations of demands and control).

We created the indicator of effort-reward imbalance by calculating the ratio between the sum response score in the effort scale and the sum response score in the reward scale. ${ }^{13-15}$ We divided the resulting quotient into thirds to indicate low, intermediate, and high effort-reward imbalance.

We observed an association between job strain and effort-reward imbalance. Employees with high job strain reported high effort-reward imbalance more often than employees with intermediate and low job strain $(60 \%$ v $28 \%$ v 13\%; weighted $\kappa=0.32, \mathrm{P}<0.001)$.

\section{Cardiovascular mortality}

We collected mortality data from the Statistics Finland national mortality register, using the participants' personal identification codes. We obtained the date and cause of death for all participants who died between the date of their clinical examination (which took place between 5 February and 30 June 1973) and 1 November 2000 . The causes of death were coded according to the ICD-8 (international classification of diseases, eighth revision) in 1973-86, the ICD-9 in 1987-95, and the ICD-10 in 1996-2000. Statistics Finland provided a classification that converted the different codes (up to 1997; subsequent deaths were classified on the basis of the death certificates) to the following categories: ischaemic heart diseases (I20-I25 in ICD-10), other heart diseases (I30-I52), cerebrovascular diseases (I60I69), and other diseases of the cardiovascular system (I00-I19, I26-I29, I70-I99). We pooled these categories to indicate death due to cardiovascular diseases. We used information on the basic cause of death.

\section{Demographic, behavioural, and biological factors}

We measured baseline covariates in standard ways: sex, age, occupational group (managers, other office staff, skilled workers, semiskilled workers) ${ }^{16}$ smoking status (current smoker, non-smoker), physical activity, systolic blood pressure ( $\mathrm{mm} \mathrm{Hg}$ ), serum total cholesterol concentration $(\mathrm{mmol} / \mathrm{l})$, and body mass index $\left(\mathrm{kg} / \mathrm{m}^{2}\right)$. We divided the distributions of the last four measures into thirds. We based the assessment of physical activity and diabetes on a detailed interview described elsewhere. ${ }^{17}$

At the five year follow up we measured systolic blood pressure and serum total cholesterol concentration. We measured body mass at the 10 year follow up.

\section{Statistical analysis}

We used Cox proportional hazard models to assess associations between baseline characteristics and cardiovascular mortality. The first step studied associations of age (18-27 years, 28-47 years, 48 years or over), sex, occupational group, smoking status, and other behavioural and biological factors (physical activity, systolic blood pressure, serum total cholesterol, and body mass index; all indicators divided into thirds) with cardiovascular mortality.

In the second step, we explored the associations of each work stress variable (job strain, effort-reward imbalance, and their components) with cardiovascular mortality. As the interactions between sex and work stress variables were not significant $(P>0.10)$, we based all analyses on a combined sample of male and female employees. We used the employees in the most favourable third for each work stress variable as the reference group. We adjusted hazard ratios and 95\% confidence intervals for age, sex, occupational group, and significant behavioural and biological predictors of cardiovascular mortality. We repeated analyses with two subsamples: employees free from diabetes at baseline and employees whose occupational group remained unchanged at least five years after the assessment of work stress.

Finally, in order to identify potential biological linking mechanisms, we assessed associations of work stress variables with blood pressure, cholesterol concentration, and body mass index at follow up by using analysis of variance with adjustment for baseline values of these biological factors, age, and sex. We treated biological factors as continuous variables here. We used the SAS 8.12 statistical program package to perform all analyses. 


\section{Results}

During the mean follow up of 25.6 (range 0.9-27.8) years, 73 deaths from cardiovascular causes occurred among the participants who had been free from overt cardiovascular diseases at baseline. Table 1 shows the associations of demographic, behavioural, and biological factors with cardiovascular mortality. As expected, higher age, male sex, low worker status, smoking, sedentary lifestyle, high blood pressure, high cholesterol concentration, and high body mass index increased the risk of death.

Table 2 presents the relative hazards for cardiovascular mortality by levels of the components of the work stress models. After adjustment for age and sex, we found excess risks for high job strain, low job control, high effort-reward imbalance, and low reward, but not for high demands or high efforts.

After additional adjustment for occupational group, job control no longer predicted mortality, as shown in table 3 . The hazard ratio for the reward component also became non-significant after adjustment for behavioural risk factors. Adjustment for baseline covariates had little effect on the associations of job strain and effort-reward imbalance with cardiovascular mortality. The fit was the same for both these models ( -2 log likelihood statistics were 786.4 for job strain and 787.8 for effort-reward imbalance). Employees scoring high on job strain and effort-reward imbalance had a twofold risk of death compared with their colleagues with low strain and low effort-reward imbalance (table 3). Exclusion from the analyses of the four participants who had diabetes at baseline did not change these results.

A stratified analysis of the 584 employees (55 deaths) whose occupational group remained unchanged five years after the assessment of work stress revealed a strengthened association between job strain and cardiovascular mortality-the hazard ratio for high job strain was 2.90 (95\% confidence interval 1.25 to 6.71 ). The association between reward-effort imbalance and mortality remained unaltered-hazard ratio for high imbalance of 2.59 (1.18 to 5.68). The individual components of the work stress models were not significantly associated with death from cardiovascular disease.

Table 4 shows increased concentrations of total cholesterol at follow up for employees with high job strain and low job control, and increased body mass index for employees with low job control and high effort-reward imbalance. Work stress was not associated with blood pressure at follow up.

\section{Discussion}

To our knowledge, this is the first study of cardiovascular mortality that tests the validity of the two main work stress models in a single working population. We found that employees reporting high job strain and high effort-reward imbalance had a twofold higher risk of death from cardiovascular disease than their colleagues scoring low in these dimensions. The specific strengths of our investigation were a long follow up period, comprehensive questionnaires to indicate stressful work characteristics, control for a
Table 1 Hazard ratios for cardiovascular mortality with demographic, behavioural, and biological factors

\begin{tabular}{|c|c|c|}
\hline Characteristic & $\begin{array}{l}\text { No of participants (No } \\
\text { of deaths) }\end{array}$ & Hazard ratio $(95 \% \mathrm{Cl})$ \\
\hline \multicolumn{3}{|l|}{ Age at baseline (years): } \\
\hline$\leqslant 27$ & $251(3)$ & 1.00 \\
\hline $28-47$ & $330(13)$ & 3.37 (0.96 to 11.82$)$ \\
\hline$>47$ & $231(57)$ & 26.48 (8.29 to 84.61$)$ \\
\hline \multicolumn{3}{|l|}{ Sex: } \\
\hline Women & 267 (13) & 1.00 \\
\hline Men & $545(60)$ & 2.41 (1.32 to 4.39$)$ \\
\hline \multicolumn{3}{|l|}{ Occupational group: } \\
\hline Managers & $94(5)$ & 1.00 \\
\hline Other office staff & $269(19)$ & $1.29(0.48$ to 3.46$)$ \\
\hline Skilled workers & $165(24)$ & 2.86 (1.09 to 7.49$)$ \\
\hline Semiskilled workers & $284(25)$ & 1.63 (0.62 to 4.26$)$ \\
\hline \multicolumn{3}{|l|}{ Smoking status: } \\
\hline Non-smoker & $560(39)$ & 1.00 \\
\hline Current smoker & $251(34)$ & 2.17 (1.37 to 3.44$)$ \\
\hline \multicolumn{3}{|l|}{ Physical activity level: } \\
\hline Low & $364(44)$ & 1.00 \\
\hline Intermediate & $171(15)$ & 0.71 (0.39 to 1.27$)$ \\
\hline High & 277 (14) & 0.39 (0.21 to 0.71$)$ \\
\hline \multicolumn{3}{|c|}{ Systolic blood pressure $(\mathrm{mm} \mathrm{Hg})$ : } \\
\hline$<127$ & $255(9)$ & 1.00 \\
\hline $127-143$ & 301 (14) & $1.31(0.57$ to 3.03$)$ \\
\hline$>143$ & $256(50)$ & 6.21 (3.05 to 12.63$)$ \\
\hline \multicolumn{3}{|l|}{ Cholesterol (mmol//): } \\
\hline$<5.6$ & $286(8)$ & 1.00 \\
\hline $5.6-6.8$ & $268(26)$ & 3.68 (1.66 to 8.12$)$ \\
\hline$>6.8$ & $258(39)$ & $5.94(2.77$ to 12.70$)$ \\
\hline \multicolumn{3}{|c|}{ Body mass index $\left(\mathrm{kg} / \mathrm{m}^{2}\right)$ : } \\
\hline$<23$ & $267(13)$ & 1.00 \\
\hline $23-25.5$ & $268(24)$ & $1.92(0.98$ to 3.77$)$ \\
\hline$>25.5$ & 277 (36) & $2.88(1.53$ to 5.42$)$ \\
\hline
\end{tabular}

Table 2 Hazard ratios for cardiovascular mortality by levels of work characteristics. Adjusted for age and sex

\begin{tabular}{|c|c|c|}
\hline Characteristic & $\begin{array}{c}\text { No of participants (No } \\
\text { of deaths) }\end{array}$ & Hazard ratio $(95 \% \mathrm{CI})$ \\
\hline \multicolumn{3}{|l|}{ Job strain: } \\
\hline Low & $215(16)$ & 1.00 \\
\hline Intermediate & $389(32)$ & 1.53 (0.83 to 2.82$)$ \\
\hline High & $201(25)$ & 2.20 (1.16 to 4.17$)$ \\
\hline \multicolumn{3}{|c|}{ Demands (a component of job strain): } \\
\hline Low & $298(23)$ & 1.00 \\
\hline Intermediate & $232(22)$ & $1.58(0.88$ to 2.84$)$ \\
\hline High & $282(28)$ & 1.35 (0.77 to 2.36$)$ \\
\hline \multicolumn{3}{|c|}{ Job control (a component of job strain): } \\
\hline High & $264(20)$ & 1.00 \\
\hline Intermediate & $259(21)$ & $1.17(0.63$ to 2.16$)$ \\
\hline Low & $282(32)$ & 1.90 (1.08 to 3.37$)$ \\
\hline \multicolumn{3}{|c|}{ Effort-reward imbalance: } \\
\hline Low & $269(15)$ & 1.00 \\
\hline Intermediate & $272(29)$ & 2.21 (1.17 to 4.15$)$ \\
\hline High & $271(29)$ & 2.36 (1.26 to 4.42$)$ \\
\hline \multicolumn{3}{|c|}{ Effort (a component of effort-reward imbalance): } \\
\hline Low & $263(17)$ & 1.00 \\
\hline Intermediate & $277(24)$ & 1.54 (0.82 to 2.90$)$ \\
\hline High & $272(32)$ & $1.63(0.90$ to 2.96$)$ \\
\hline \multicolumn{3}{|c|}{ Reward (a component of effort-reward imbalance): } \\
\hline High & $280(32)$ & 1.00 \\
\hline Intermediate & $252(14)$ & 0.79 (0.41 to 1.51$)$ \\
\hline Low & $280(27)$ & 2.04 (1.21 to 3.43 ) \\
\hline
\end{tabular}

large set of potential confounding factors, and the use of reliable mortality registers.

In this study of initially healthy employees adjustment for baseline variation in smoking, seden- 
Table 3 Adjusted hazard ratios (95\% confidence intervals) for cardiovascular mortality by levels of work characteristics

\begin{tabular}{|c|c|c|c|c|}
\hline \multirow[b]{2}{*}{ Characteristic } & \multicolumn{4}{|c|}{ Covariates in addition to age and sex } \\
\hline & Occupational group & Behavioural risk factors* & Biological risk factorst & All aforementioned \\
\hline \multicolumn{5}{|l|}{ Job strain: } \\
\hline Low & 1.00 & 1.00 & 1.00 & 1.00 \\
\hline Intermediate & 1.36 (0.72 to 2.57$)$ & 1.71 (0.92 to 3.17$)$ & 1.58 (0.84 to 2.95$)$ & 1.64 (0.85 to 3.19$)$ \\
\hline High & $1.89(0.93$ to 3.81$)$ & 2.20 (1.12 to 4.32$)$ & 2.35 (1.22 to 4.52$)$ & 2.22 (1.04 to 4.73$)$ \\
\hline \multicolumn{5}{|c|}{ Job control (a component of job strain): } \\
\hline High & 1.00 & 1.00 & 1.00 & 1.00 \\
\hline Intermediate & 0.94 (0.48 to 1.82$)$ & $1.06(0.57$ to 1.98$)$ & $1.14(0.62$ to 2.11$)$ & $0.74(0.39$ to 1.50$)$ \\
\hline Low & $1.55(0.80$ to 3.01$)$ & 1.79 (0.98 to 3.27$)$ & 1.89 (1.06 to 3.38$)$ & $1.42(0.72$ to 2.82$)$ \\
\hline \multicolumn{5}{|c|}{ Effort-reward imbalance: } \\
\hline Low & 1.00 & 1.00 & 1.00 & 1.00 \\
\hline Intermediate & 2.16 (1.04 to 4.49$)$ & 2.00 (1.06 to 3.78$)$ & 2.07 (1.09 to 3.91$)$ & 1.91 (0.90 to 4.05$)$ \\
\hline High & 2.36 (1.06 to 5.46$)$ & 2.18 (1.15 to 4.13$)$ & 2.29 (1.21 to 4.35$)$ & 2.42 (1.02 to 5.73$)$ \\
\hline
\end{tabular}

${ }^{*}$ Smoking and physical activity.

†Systolic blood pressure, cholesterol concentration, and body mass index.

tary lifestyle, blood pressure, serum total cholesterol, body mass index, and history of diabetes resulted in no or only a minor attenuation of hazard ratios. However, high job strain and high effort-reward imbalance were associated with increased cholesterol concentration and body mass index at follow up. These associations may reflect pathophysiological changes related to the development of cardiovascular disease.

The work stress models are aimed at identifying characteristics of work life that are likely to cause frequent and longlasting stress and therefore be predictive of disease endpoints. ${ }^{18}$ Stable levels of work stress are more likely among employees who do not change their job or workplace. In line with this, we found the adverse effects of high job strain to be greatest for employees who remained with the same employer and in the same occupation during the five years after assessment of their work stress. The results for effort-reward imbalance remained unaltered in this stratified analysis.

Many recent studies on the job strain model emphasise the importance of low job control rather than its interaction with high demands. ${ }^{19}$ We found low job control to be associated with cardiovascular mortality before, but not after, adjustment for occupational group. The $40 \%$ attenuation in the hazard ratio after the adjustment suggests that job control varies according to occupational group or that part of the effect of job control may be attributable to its relation to low socioeconomic status, a major determinant of

Table 4 Serum total cholesterol concentration and body mass index at follow up* by levels of work characteristics. Means are adjusted for baseline value, sex, and age

\begin{tabular}{|c|c|c|c|c|}
\hline \multirow[b]{2}{*}{ Characteristic } & \multicolumn{2}{|c|}{$\begin{array}{l}\text { Serum total cholesterol } \\
(\mathrm{mmol} / / \times 100)\end{array}$} & \multicolumn{2}{|c|}{ Body mass index $\left(\mathrm{kg} / \mathrm{m}^{2}\right)$} \\
\hline & Mean (SE) & $P$ value & Mean (SE) & $P$ value \\
\hline Job strain: & & 0.050 & & 0.151 \\
\hline Low & $634.6(6.28)$ & & $24.8(0.14)$ & \\
\hline Intermediate & $649.0(4.34)$ & & $25.1(0.10)$ & \\
\hline High & $655.8(6.07)$ & & $25.2(0.15)$ & \\
\hline Job control (a component of job strain): & & 0.033 & & 0.008 \\
\hline High & $635.2(5.54)$ & & $24.7(0.13)$ & \\
\hline Intermediate & $653.8(5.35)$ & & $25.1(0.13)$ & \\
\hline Low & $651.7(5.16)$ & & $25.3(0.12)$ & \\
\hline Effort-reward imbalance: & & 0.168 & & 0.002 \\
\hline Low & $639.0(5.48)$ & & $24.8(0.12)$ & \\
\hline Intermediate & $652.0(5.25)$ & & $25.1(0.12)$ & \\
\hline High & $651.1(5.15)$ & & $25.4(0.13)$ & \\
\hline
\end{tabular}

*Five year follow up of cholesterol and 10 year follow up of body mass. public health. ${ }^{20}{ }^{21}$ Our results are in line with those of Lynch et al, who reported that the effect of low resources (a construct close to job control) on mortality and acute myocardial infarction was evident only for employees with low socioeconomic status. ${ }^{9}$

High work demands and high mobilisation of efforts at work may not always indicate harmful stress. In this study, the levels of demands and effort did not independently predict cardiovascular mortality, and corresponding results have been reported previously. ${ }^{80-12} 22$ However, people with a very high workload, as indicated by working continuously over 11 hours a day, may be at increased risk of cardiovascular disease. ${ }^{23}$

Assessment of work stress with self reports is apparently not a source of major bias in our study. Previous studies using subjective and objective methods have tended to give reasonably consistent results, ${ }^{19}$ and the correlations between subjective assessments and expert ratings of job conditions are high. ${ }^{5}$

\section{Policy implications}

In the promotion of cardiovascular health, the traditional advice for people to stop smoking, cut down drinking, eat less fat, and engage in physical activity has been shifted towards a more holistic view. Structural and psychosocial factors, in addition to behavioural ones, are increasingly seen as important determinants of public health. Our findings on work stress are consistent with this interpretation.

However, excess health risk in employees with high stress might not exclusively reflect a causal relation. For example, a selection into a stressful work environment may partly reflect early risk factors and adverse environments during childhood and adolescence. ${ }^{24}$ Research on organisational interventions is needed to evaluate the additional gains achievable from efforts to change work life.

\section{Conclusions}

This prospective cohort study on industrial employees sheds more light on the potential causative role of work stress in cardiovascular disease. The finding of a twofold higher cardiovascular mortality risk among people with high job strain and effort-reward imbalance supports the theoretical models of Karasek, Theorell, ${ }^{2}$ and Siegrist. ${ }^{3}$ 


\section{What is already known on this topic}

Job strain (high demands and low job control) and effort-reward imbalance (high demands, low security, few career opportunities) elicit stress at work

Their status as risk factors for cardiovascular mortality has, however, remained uncertain

\section{What this study adds}

Job strain and effort-reward imbalance were each associated with a doubling of the risk of cardiovascular death among employees who were free from overt cardiovascular diseases at baseline

Job strain and effort-reward imbalance also predicted adverse changes in biological factors such as cholesterol concentration and body mass index

MK is also a senior researcher at the Finnish Institute of Occupational Health, Helsinki. We thank Hans Helenius for his help with statistical analysis.

Contributors: MK formulated the hypotheses, designed the study, carried out the data analyses, and was the principal author of the paper. PL-A is the coordinator of the project and the second principal investigator; she helped in developing the hypotheses, designing the study, data analysis, interpreting the results, and writing the paper. MK and PL-A will act as guarantors for the paper. RL, HR, JV, and JK took part in the study design, contributed to interpretation of the data, and edited the manuscript.

Funding: Grants from the Academy of Finland (project number 70139) and the Ministry of Education, Finland (188/722/2000). $\mathrm{MK}$ and JV were supported by the Academy of Finland (project numbers 44968 and 77560 ).

Competing interests: None declared.

1 Karasek RA. Job demands, job decision latitude and mental strain: implications for job redesign. Admin Sci Q 1979;24:285-307.

2 Karasek R, Theorell T. Stress, productivity and reconstruction of working life. New York: Basic Books, 1990.

3 Siegrist J. Adverse health effects of high-effort/low-reward conditions. J Occup Health Psychol 1996;1:27-41.
4 Schnall PL, Landbergis PA, Baker D. Job strain and cardiovascular disease. Ann Rev Public Health 1994;15:381-411.

5 Theorell T, Karasek RA. Current issues relating to psychosocial job strain and cardiovascular disease research.J Occup Health Psychol 1996;1:9-26.

6 Marmot MG, Bosma H, Hemingway H, Brunner E, Stansfeld S. Contribution of job control and other risk factors to social variation in coronary heart disease incidence. Lancet 1997;350:235-9.

7 Cheng Y, Kawachi I, Coagley EH, Schwartz J, Colditz G. Association between psychological work characteristics and health functioning in American women: prospective study. BMJ 2000;320:1432-6.

8 Alterman T, Shekelle RB, Vernon SW, Burau KD. Decision latitude, psychological demands, job strain, and coronary heart disease in the Western Electric study. Am J Epidemiol 1994;139:620-7.

9 Lynch J, Krause N, Kaplan GA, Tuomilehto J, Salonen JT. Workplace conditions, socioeconomic status, and the risk of mortality and acute myocardial infarction: the Kuopio ischemic heart disease risk factor study. Am J Public Health 1997;87:617-22.

10 Steenland K, Johnson J, Nowlin S. A follow up study of job strain and heart disease among males in the NHANES1 population. Am J Ind Med 1997;31:256-60.

11 Suadicani P, Hein HO, Gynetelberg F. Are social inequalities associated with the risk of ischaemic heart disease a result of psychosocial working conditions? Atherosclerosis 1993;101:165-75.

12 Bosma H, Peter R, Siegrist J, Marmot M. Two alternative job stress models and the risk of coronary heart disease. Am J Public Health 1998;88: 68-74.

13 Peter R, Alfredsson L, Hammar N, Siegrist J, Theorell T, Westerholm P. High effort, low reward, and cardiovascular risk factors in employed Swedish men and women: baseline results from the WOLF study. J Epidemiol Community Health 1998;52:540-7.

14 Vrijkotte TGM, van Doornen LJP, de Geus EJC. Work stress and metabolic and hemostatic risk factors. Psychosom Med 1999;61:796-805.

15 Vrijkotte TGM, van Doornen LJP, de Geus EJC. Effects of work stress on ambulatory blood pressure, heart rate, and heart rate variability. Hypertension 2000;35:880-6.

16 METELI. Health examination: sampling, methods and implementation. Jyväskylä, Finland: Research Institute of Physical Culture and Health, 1975. (Report no 9.) [In Finnish with English summary]

17 Leino PI. Does leisure time physical activity prevent low back disorders? Spine 1993;18:863-71.

18 McEwen BS. Protective and damaging effects of stress mediators. $N$ Engl J Med 1998;338:171-9.

19 Hemingway H, Marmot M. Psychosocial factors in the aetiology and prognosis of coronary heart disease: systematic review of prospective cohort studies. BMJ 1999:318:1460-7.

20 Marmot MG, Smith GD, Stansfeld S, Patel C, North F, Head J, et al. Health inequalities among British civil servants: the Whitehall II study. Lancet 1991;337:1387-93

21 Theorell T, Tsútsumi A, Hallquist J, Reuterwall C, Hogstedt C, Fredlund P, et al. Decision latitude, job strain, and myocardial infarction: a study of working men in Stockholm. Am J Public Health 1998;88:382-8.

22 Reed DM, Lacroix AZ, Karasek RA, Miller D, MacLean CA. Occupational strain and the incidence of coronary heart disease. Am J Epidemiol 1989;129:495-502.

23 Sokejima S, Kagamimori S. Working hours as a risk factor for acute myocardial infarction in Japan: case-control study. BMJ 1998;317:775-80.

24 Leon DA, Lithell HO, Vagero D, Koupilova I, Mohsen R, Berglund L, et al. Reduced fetal growth rate and increased risk of death from ischaemic heart disease: cohort study of 15000 Swedish men and women born 1915-29. BMJ 1998;317:241-5.

(Accepted 23 May 2002) 


\section{What is already known on this topic}

The most recent systematic review evidence suggests that self help interventions designed specifically for pregnant smokers can be effective in increasing cessation rates

These reviews, however, are based mainly on efficacy trials involving staff who are specifically employed to provide the intervention

In other attempts to assess the effectiveness of such an approach within routine antenatal care, it has been difficult to implement scientifically rigorous evaluations

\section{What this study adds}

A low cost, self help intervention was ineffective when implemented during routine antenatal care, even though it was acceptable to midwives and pregnant women

Validated smoking cessation rates among pregnant women are substantially lower than the self reported rates on which current smoking policy is based

associations between social inequality and continued smoking by pregnant women show that more complex interventions that take full account of the social and cultural circumstances of this target group are required. ${ }^{13}$

\section{Implications for policy}

Midwives will always have an important role in encouraging pregnant women to stop smoking, but if the government's target of a reduction from $23 \%$ to $15 \%$ in the percentage of women who smoke during pregnancy is to be met by the year 2010, more intensive interventions or interventions provided by dedicated staff will be required. ${ }^{14}$ The discrepancy between biochemically validated and self reported quit rates highlights the importance of biochemical validation. This calls into question the adequacy of monitoring of the government's target for smoking in pregnancy, which currently relies on retrospective self reported smoking behaviour. ${ }^{15}$

We thank all the midwives and pregnant women who participated so willingly in the trial, and the three NHS trusts for their cooperation. We also thank the members of the Trial Steering Group, Tim Peters, Leslie Davidson, Paul Little, and Mavis Kirkham for their helpful advice and guidance; Paul Harker for assistance in developing the intervention and research proposal; and Jenny Donovan for helpful comments on a draft of this paper.

Contributors: See bmj.com

Funding: The Medical Research Council funded the trial. Dorset Health Authority funded the development of the intervention materials.

Competing interests: None declared.

1 Health Education Authority. Smoking and pregnancy: guidance for purchasers and providers. London: HEA, 1993.

2 Dolan-Mullen P, Ramirez G, Groff JY. A Meta-analysis of randomized trials of prenatal smoking cessation interventions. Am J Obstet Gynaecol 1994;171:1328-34

3 Walsh R, Redman S. Smoking cessation in pregnancy: do effective programmes exist? Health Promot Internation 1993;8:111-27.
4 Lumley J. Strategies for reducing smoking in pregnancy. In: Enkin MW, Keirse MJNC, Renfrew MJ, Neilson JP, eds. Pregnancy and Childbirth Module. Cochrane Library. Oxford, Update Software, 1994 (Review Nos 03312 and 03397 )

5 Sexton M, Hebel JR. A clinical trial of change in maternal smoking and its effect on birth weight. JAMA 1984;251:911-5.

6 Windsor RA, Cutter G, Morris J, Reese Y, Manzella B, Bartlett EE, et al The effectiveness of smoking cessation methods for smokers in public health maternity clinics: a randomised trial. Am J Public Health 1985:75;1389-92.

7 Windsor RA, Lowe JB, Perkins LL, Smith-Yoder D, Artz L, Crawford M, et al. Health education for pregnant smokers: its behavioral impact and cost benefit. Am J Public Health 1993;83:201-6.

8 Petersen L, Handel J, Kotch J, Podedworny T, Rosen A. Smoking reduction during pregnancy by a program of self-help and clinical support. Obstet Gynecol 1992:79;924-30.

9 Hjalmarson AIM, Hahn L, Svanberg B. Stopping smoking in pregnancy: effect of a self-help manual in controlled trial. $\mathrm{Br} J$ Obstet Gynaecol 1991:98;260-4.

10 Ershoff DH, Mullen PD, Quinn VP. A randomised trial of a serialized selfhelp smoking cessation program for pregnant women in an HMO. AmJ Public Health 1989;79:182-7.

11 Fitzmaurice DA. Written information for treating minor illness. $B M J$ 2001;322:1193-4.

12 Mant D. Health promotion and disease prevention. In: Peckham M, Smith R, eds. Scientific basis of health services. London: BMJ Publishing Group, 1996:170-8.

13 Oliver S, Oakley L, Lumley J, Waters E. Smoking cessation programmes in pregnancy: systematically addressing development, implementation, women's concerns and effectiveness. Health Educ J 2001;60:362-70.

14 Secretary of State for Health. Smoking kills. A white paper on tobacco. London: Stationery Office, 1998.

15 Owen L, McNeill A. Saliva cotinine as indicator of cigarette smoking in pregnant women. Addiction 2001;96:1001-6.

\section{Corrections and clarifications}

Work stress and risk of cardiovascular mortality: prospective cohort study of industrial employees A lapse in concentration at proof stage of this paper by Mika Kivimäki and colleagues (19 October, pp 857-60) led us to assign the wrong address to some authors. The correct affiliation for Päivi Leino-Arjas, Ritva Luukkonen, and Hilkka Riihimäki is the Department of Epidemiology and Biostatistics, Finnish Institute of Occupational Health, Helsinki, Finland, and for Jussi Vahtera is the Turku Regional Institute of Occupational Health, Finland. Our apologies for getting these wrong.

Career focus

Two editorial errors crept into the article "Induction courses for international doctors" by Martha Swierczynski (16 November, p s159). In trying to clarify the meaning of the phrase "international doctors," we added (in the opening paragraph) "doctors who have trained in the United Kingdom." This is clearly wrong; what we had intended to add was "doctors who have trained outside the United Kingdom." Also, in the last paragraph of the section "Eligibility for induction courses" the penultimate sentence should read "Trusts [not deaneries] are advised to make the courses as accessible as possible."

Nurse led follow up and conventional medical follow up in management of patients with lung cancer: randomised trial

In this paper by Sally Moore and colleagues (16 November, pp 1145-7), the affiliation for Mary Wells was out of date. She has informed us that for the past three years she has been a clinical research fellow in cancer nursing at the School of Nursing and Midwifery, University of Dundee. 